\title{
应用储层流体包裹体信息研究天然气 气藏的成藏时间
}

肖贤明刘祖发刘德汉 米敬奎申家贵宋之光 (中国科学院广州地球化学研究所有机地球化学国家重点实验室, 广州 510640. E-mail: xmxiao@gig.ac.cn)

\begin{abstract}
摘要以鄂尔多斯盆地晚古生代深盆气藏为例, 应用储层中流体包裹体均一温度及其他信息, 结合该 盆地古地温演变与沉积构造史, 推算出该气藏成藏时间为 $150 \sim 125 \mathrm{Ma}$, 并且具有南部早北部晚的特 点. 这一结论与鄂尔多斯盆地晚古生代气藏形成的地质地球化学条件相吻合.
\end{abstract}

\section{关键词 流体包裏体 成藏年代学 鄂尔多斯盆地 深盆气藏}

天然气成藏年代学是天然气地质研究最薄弱的 环节. 目前主要依据 ${ }^{3} \mathrm{He} /{ }^{4} \mathrm{He}$ 及 ${ }^{40} \mathrm{Ar} /{ }^{36} \mathrm{Ar}$ 比值与天然 气成藏年代的关系确定天然气成藏年代 ${ }^{[1 \sim 3]}$. 该方法 主要缺点是: (1) 往往只能得到相对年龄值, 或是气 源岩年龄; (2) 在国内, 天然气 ${ }^{3} \mathrm{He} /{ }^{4} \mathrm{He}$ 及 ${ }^{40} \mathrm{Ar} /{ }^{36} \mathrm{Ar}$ 同 位素测定只有很少几个实验室能完成.

近年来，在国内外均有文献报道应用储层中有 机包裹体均一温度, 结合沉积构造演化史确定含油 气盆地油气藏形成时间 ${ }^{[4,5]}$. 然而, 这一方法很少应 用于气藏研究. 目前主要依据烃源岩生气期与圈闭 形成期的时空匹配关系, 并结合其他地质条件来推 算天然气成藏时间 ${ }^{[6,7]}$.

鄂尔多斯盆地晚古生代气藏储层中存在大量有 机包裹体及盐水包裹体, 这些不同类型包裹体蕴藏 了丰富的天然气成因信息, 并与天然气成藏年代有 密切关系. 本文以该气藏为例, 试图应用储层包裹体 信息研究天然气藏的成藏时间.

\section{1 原理与方法}

沉积盆地岩石中自生矿物包裹体的形成有一个 必备条件是必须存在丰富的地层孔隙水, 只有地层 中含有成矿流体, 才有可能形成大量包裹体 ${ }^{[8,9]}$. 天 然气成藏过程是天然气注人储层, 不断驱替储层中 的孔隙水, 最后聚集成藏. 相应地, 储层中的包裹体 形成演化过程为: (1) 天然气进人储层前, 形成盐水 包裹体; (2) 天然气开始注人储层, 形成含气态烃包裹 体并与盐水包裹体及气态烃包裹体共生; (3) 气藏形 成后, 储层中孔隙水被驱替, 一般不再形成包裹体. 显然, 盐水包裹体与气态烃包裹体共生的情况出现 于天然气成藏过程. 因此, 这些包裹体形成时间代表
了天然气大规模进入储层的时间, 按地质学精度, 也 可作为天然气成藏的地质时间.

根据盐水溶液包体均一温度, 结合盆地古地温 史、沉积史，盐水包裹体形成时间(即气藏形成时间) 可按如下步骤确定：(1) 测定与气态烃包裹体共生盐 水包裹体的均一温度; (2) 确定这组盐水包裹体的形 成深度, 推算公式为 $H=\left(T_{\mathrm{H}}-T_{0}\right) / \mathrm{PGT}$, 其中 $H$ 为形 成深度, $T_{\mathrm{H}}$ 为样品盐水溶液包裹体的均一温度, $T_{0}$ 为 古地表温度, PTG 为古地温梯度; (3) 确定形成时间, 如后文中图 2(c)所示鄂尔多斯盆地晚古生代天然气 气藏陕 13 井早二叠世储层砂岩样品中盐水溶液包裹 体形成时间推算方法. 应用埋藏史及古地温梯度确 定该样品所经历的古地温演化, 得到相应曲线. 该样 品盐水包裹体均一温度平均值为 $130^{\circ} \mathrm{C}$, 从该温度值 与古地温演化曲线的交叉点向 $X$ 轴引垂线, 与 $X$ 轴交 点为 $132 \mathrm{Ma}$, 即该组盐水包裹体形成时间, 亦代表 该气藏形成时间.

\section{2 鄂尔多斯盆地晚古生代气藏形成时间推算}

\section{1 区域地质背景}

鄂尔多斯盆地晚古生代地层为一套海陆交互相 含煤岩系, 构成一套相对独立的含油气系统 ${ }^{[10]}$, 气 源岩为广泛分布的石炭-二叠系含煤岩系, 储层为石 炭-二叠系致密砂岩. 鄂尔多斯盆地整体构造格局为 东高西低、北高南低，北、东斜坡带构造平缓. 天然 气聚集在广大斜坡部位, 整体构成区域性水动力圈 闭, 形成气、水倒置关系. 据这些特征, 不少学者提 出它是一个深盆气藏 ${ }^{[113]}$. 近年来, 对该气藏形成 的气源条件、运聚动力学及气水倒置机理等问题作了 /矢量研究 
一些相关研究主要是从气源岩生气期及其与圈闭构 造形成时间的匹配关系加以推断 ${ }^{[13,14]}$. 本研究以该 气藏为例, 试图应用储层流体包裹体特征来研究气 藏成藏时间.

\section{2 样品与实验}

本研究钻孔主要分布在鄂尔多斯盆地中北部一 个南北向剖面, 跨越气带、气水过渡带及水带. 样品 主要取自石炭-二叠系煤层及早二叠世砂岩储层钻孔 岩芯(图 1).

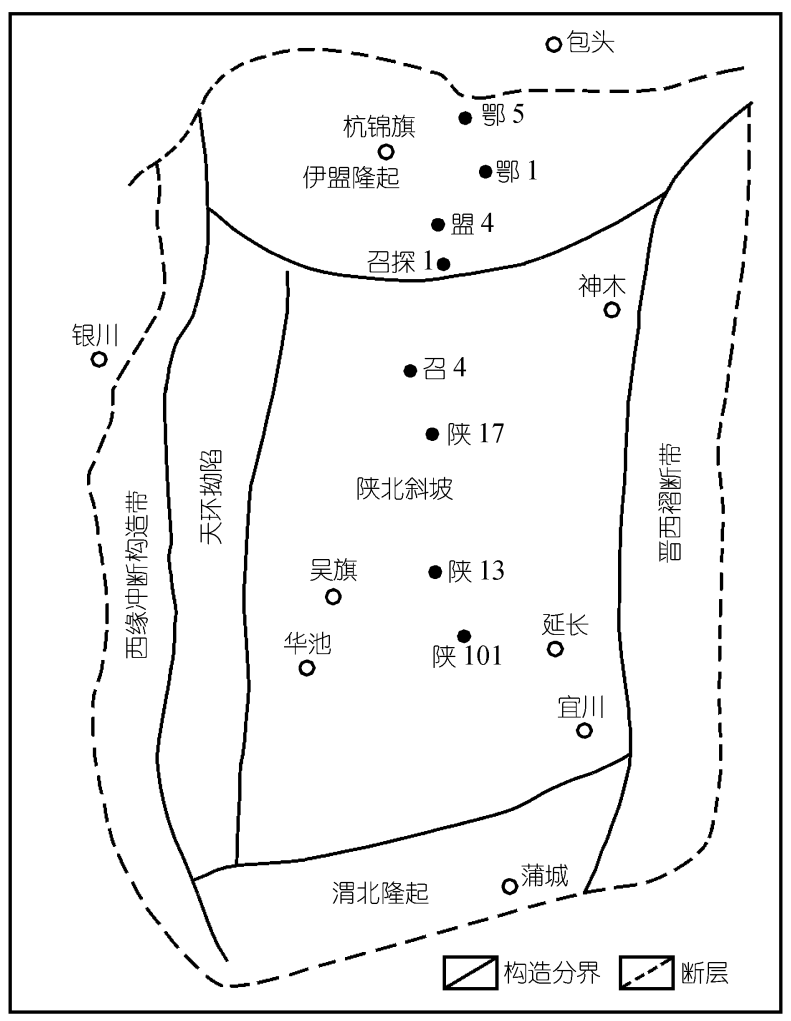

图 1 本研究钻孔分布略图
煤样主要用作镜质组反射率测定, 储层砂岩主 要用作包裹体观测. 砂岩孔隙度低、致密、胶结物中 包裹体较少. 砂岩中的石英颗粒细微裂隙发育, 含有 大量次生包裹体. 为保证结果的应用价值, 本研究仅 测定了石英颗粒次生裂隙中与气态烃包裹体共生的 盐水包裹体的均一温度. 使用美国地质调查所发明 的气流冷热台, 均一温度误差范围 $1.0^{\circ} \mathrm{C}$. 因实测均 一温度均不到 $250^{\circ} \mathrm{C}$, 故未作压力校正.

\section{3 储层中包裹体类型}

早二叠世砂岩储层中包裹体十分丰富，可分为 3 类: (1) 盐水包裹体: 数量多, 分布广. 气带钻孔样品 中常见盐水溶液包裹体与气态包裹体共生. 又可进 一步分为液体包裹体、液体 $\mathrm{CO}_{2}$ 包裹体及含子矿物 的包裹体 3 类. (2) 烃类包裹体: 仅发现有气态烃包裹 体及含气态烃包裹体. 这类包裹体大小 $5 \sim 16 \mu \mathrm{m}$, 常与盐水包裹体共生, 南部样品中较多, 向北有减少 的趋势, 在鄂 5 井样品中未见这类包裹体. (3) 沸腾包 裹体: 出现于较高温、低压环境, 说明储层中压力低, 并含有较多的甲烷. 这一特点与深盆气藏成藏时呈 负压特征是一致的. 这 3 类包裹体的鉴别特征见表 1 .

鄂尔多斯盆地晚古生代砂岩储层中盐水溶液包 裹体与烃类包裹体广泛共生, 说明这组包裹体形成 于天然气运移过程中.

\section{4 盐水溶液包辠体均一温度}

从表 2 可得到如下几点规律: (1) 在气带, 样品盐 水包裹体均一温度只有一期, 平均均一温度范围为 $94 \sim 143^{\circ} \mathrm{C}$, 并具有南部样品高北部样品低的特点; (2) 在气水过渡带的钻孔, 样品均一温度范围分布较 宽, 为 $90 \sim 138^{\circ} \mathrm{C}$, 分期不是很明显; (3) 在水带仅有 鄂 5 井实测资料. 流体包体均一温度分布宽, 大致上 有两期: $88 \sim 102^{\circ} \mathrm{C}$ 和 $118 \sim 132^{\circ} \mathrm{C}$.

表 1 鄂尔多斯盆地晚古生代砂岩储层中主要不同类型包裹体鉴别特征

\begin{tabular}{|c|c|c|c|}
\hline \multirow{2}{*}{\multicolumn{2}{|c|}{ 包裹体类型 }} & \multicolumn{2}{|c|}{ 鉴别标志 } \\
\hline & & 形态 & 均一温度 $/{ }^{\circ} \mathrm{C}$ \\
\hline 盐水包裹体 & & $\begin{array}{l}\text { 大小不等, } 3 \sim 24 \mu \mathrm{m} \text {, 气、液比: } 5 \sim 20, \text { 圆形-椭圆 } \\
\text { 形, 无色透明 }\end{array}$ & $\begin{array}{l}\text { 随温度增加, 气相与液相均一化温度出现在 } 80 \sim 140^{\circ} \mathrm{C} \text {. } \\
\text { 在冷凝过程中, 冰点温度出现在 }-4 \sim 2^{\circ} \mathrm{C}\end{array}$ \\
\hline \multirow[b]{2}{*}{ 烃类包裹体 } & 气态烃包裹体 & $\begin{array}{l}\text { 大小不等, } 5 \sim 16 \mu \mathrm{m} \text {, 灰黑色, 无苂光, 在高温下 } \\
\text { 为单相 }\end{array}$ & $\begin{array}{l}\text { 冷凝过程中, 出现液相从气相中分离, 均一温度出现 } \\
\text { 在 }-50 \sim-20^{\circ} \mathrm{C}\end{array}$ \\
\hline & 含气态烃包裹体 & $\begin{array}{l}\text { 个体较大, } 8 \sim 24 \mu \mathrm{m}, \text { 透明, 气液边界清晰. 在高 } \\
\text { 温下为二相, 气态烃占 } 20 \% \sim 40 \% \text {, 形体不规则 }\end{array}$ & $\begin{array}{l}\text { 在冷凝过程中, 直到 }-100^{\circ} \mathrm{C} \text { 前气、液比无明显变化, 在 } \\
\text { 加热过程中, 出现气相与液相均一化, 均一温度 } 160 \sim \\
170^{\circ} \mathrm{C} \text {, 高于共生盐水包裹体 }\end{array}$ \\
\hline 沸腾包裹 & & $\begin{array}{l}\text { 不同气液比、不同大小的盐水包裹体与液体 } \mathrm{CO}_{2} \\
\text { 包裹体s烃类包裹体共生ina.com/doi/10.1360/c }\end{array}$ & $\begin{array}{l}\text { 在温度升高或冷凝过程中, 可见这些不同类型的包裹 } \\
\text { 体出现相应的相变 }\end{array}$ \\
\hline
\end{tabular}


表 2 鄂尔多斯盆地下二叠统砂岩储层中流体包裹体均一温度测定结果

\begin{tabular}{cccccc}
\hline 位置 & 钻井号 & 井深/m & 地层 & 温度范围 $/{ }^{\circ} \mathrm{C}$ & 平均温度 ${ }^{\circ} \mathrm{C}$ \\
\hline 水带 & 鄂 5 & 2636 & $\mathrm{P}_{1}$ & 第 1 组: $88 \sim 102$ & 100 \\
气水带 & 鄂 1 & 2760 & $\mathrm{P}_{1}$ & 第 2 组: $118 \sim 132$ & 125 \\
气水带 & 盟 4 & 2822 & $\mathrm{P}_{1}$ & $90 \sim 138$ & 103 \\
气带 & 召探 1 & 2991 & $\mathrm{P}_{1}$ & $93 \sim 118$ & 110 \\
气带 & 召探 1 & 2994 & $\mathrm{P}_{1}$ & $94 \sim 123$ & 115 \\
气带 & 召 4 & 3008 & $\mathrm{P}_{1}$ & $94 \sim 128$ & 117 \\
气带 & 召 4 & 3012 & $\mathrm{P}_{1}$ & $102 \sim 136$ & 118 \\
气带 & 召 4 & 3091 & $\mathrm{P}_{1}$ & $110 \sim 130$ & 118 \\
气带 & 陕 17 & 2878 & $\mathrm{P}_{1}$ & $103 \sim 135$ & 126 \\
气带 & 陕 13 & 2940 & $\mathrm{P}_{1}$ & $100 \sim 136$ & 130 \\
气带 & 陕 101 & 3270 & $\mathrm{P}_{1}$ & $119 \sim 138$ & 134 \\
\hline
\end{tabular}
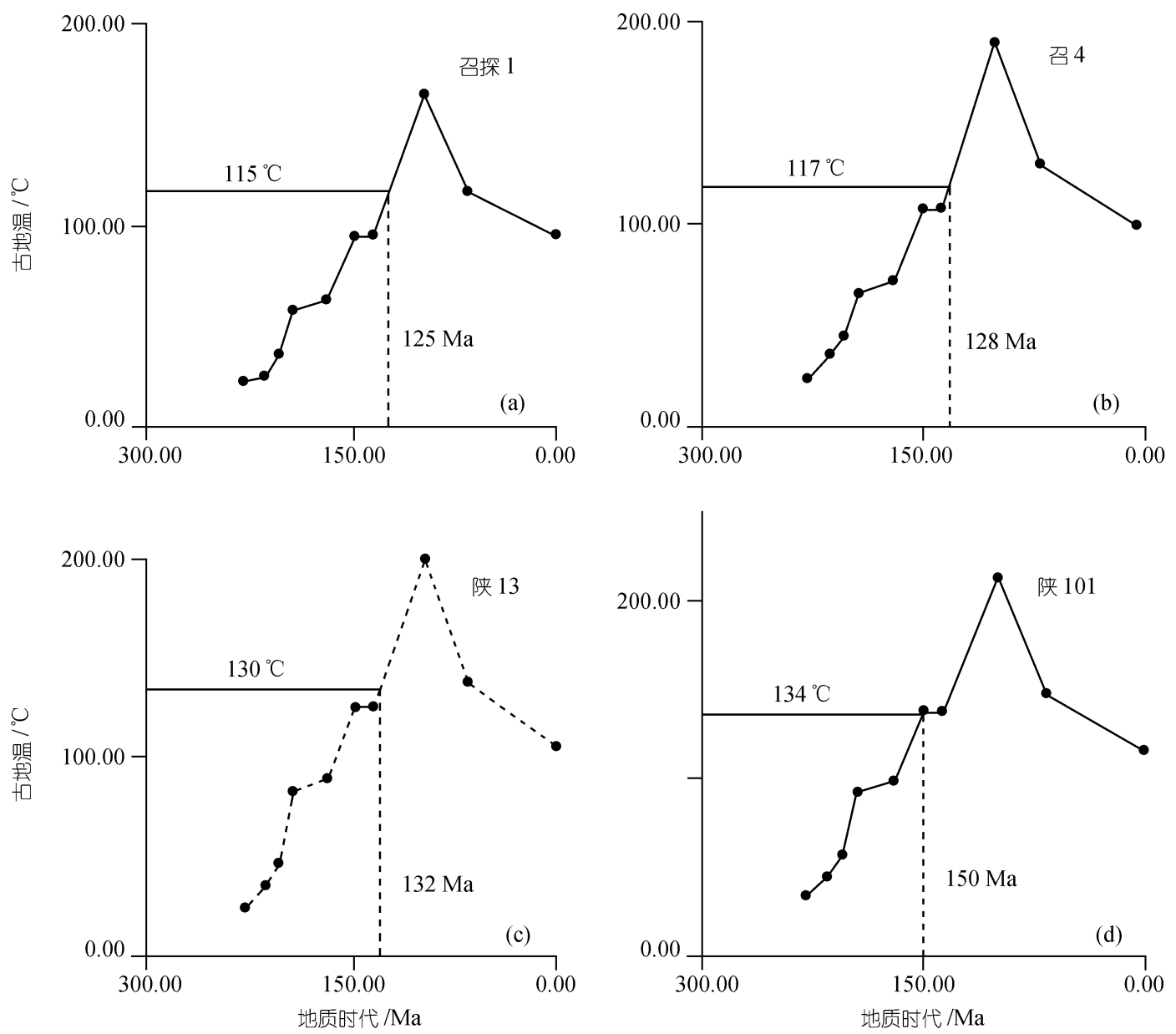

图 2 鄂尔多斯盆地晚古生代砂岩储层中流体包裹体形成时间推算图示

地层分层厚度来源于长庆油田研究院, 地层剥蚀厚度据文献[15]. 古地温梯度模式为: 中侏罗世 早白严世为 $4.0^{\circ} \mathrm{C} / 100 \mathrm{~m}^{[11,13,15]}$; 其他地质时期为 $3.0^{\circ} \mathrm{C} / 100 \mathrm{~m}$

这进一步说明在不同天然气聚集带包裹体形成 的物理化学条件不同. 在气带储层砂岩中, 天然气运 聚驱替了地层中的水, 流体包体的形成受控于气藏
成藏过程，流体包裹体形成于气藏成藏过程中或以 前, 包裹体均一温度南部样品高北部样品低. 而在水 带, 盐水包裹体的形成未受天然气运聚的影响, 在地 
层回返过程中仍有包裹体形成.

\section{5 天然气气藏形成时间推算}

根据前述研究, 应用储层中流体包裹体均一温 度, 结合埋藏史及古地温史可推断流体包裹体形成 时间，并可大致反映天然气气藏成藏时间.

图 2 是代表性钻孔储层砂岩中流体包裹体形成 时间推算结果. 由图 2 可见, 在气带这组与烃类包裹 体共生的盐水包裹体形成时间为 $125 \sim 150 \mathrm{Ma}$, 并具 有南早北晚的特点. 由此可推断天然气大量进人储 层的时间是晚侏罗世 早白严世.

\section{6 晚古生代气藏形成的地质地球化学条件}

流体包裹体所反映的天然气成藏年代信息与该 盆地油气藏形成的地质地球化学条件十分吻合. 应 用上述地温模式和实测 $\mathrm{V} R_{\mathrm{o}}$ 数据, 按 TTI 法反演烃源 岩成烃历程, 得到如图 3 所示本研究钻孔山西组煤层 $\mathrm{V} R_{\mathrm{o}}$ 值的变化规律. 如按 $\mathrm{V} R_{\mathrm{o}}=1.2 \%$ 作为大量生气 阶段的起点, 则这些钻孔煤层大量生气阶段出现在 $150 \sim 120 \mathrm{Ma}$, 并且同样具有南部早北部晚的特点, 与应用流体包裹体推算出的气藏形成时间非常吻合.

应当指出, 本方法所推断的成藏时间实际上是 天然气大量注人储层的时间, 往往天然气充注、运移 与调整需相当长时间, 应结合区域成藏地质地球化 学条件综合解释. 如鄂尔多斯盆地, 天然气充注过程 可一直持续到晚白严世 ${ }^{[15]}$.

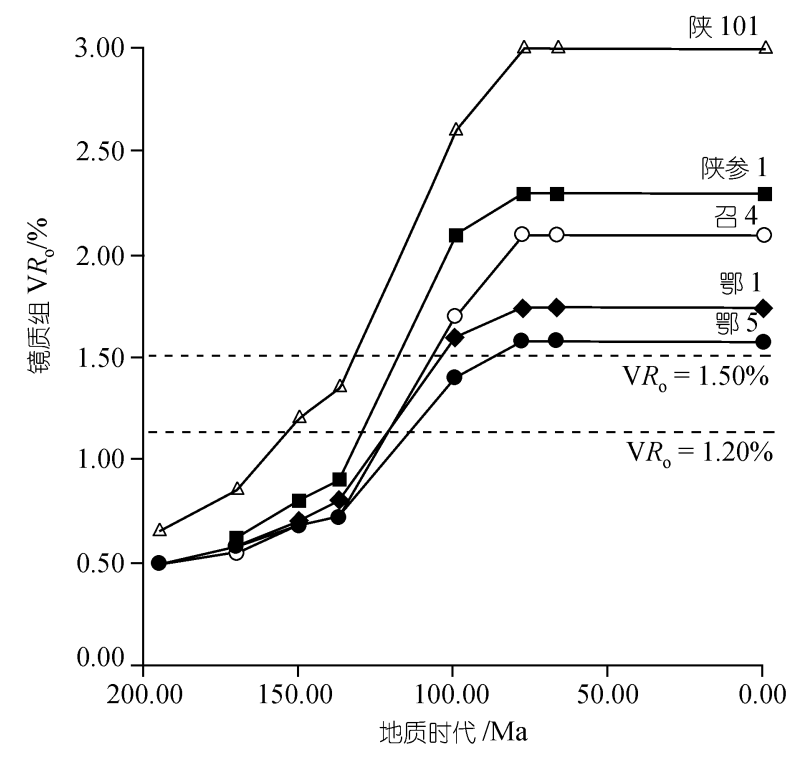

图 3 鄂尔多斯盆地某些钻孔煤层 $\mathrm{V} R_{\mathrm{o}}$ 演化规律 (按 TTI 法模拟计算)

\section{3 结论}

应用储层中流体包裹体信息，结合地质背景可 推断天然气气藏的成藏时间. 严格地讲, 它所反映的 是天然气大量注人储层的时间而反映不了整个成藏 过程. 与其他方法相比, 本方法的优点是方法较简 单、经济, 结果较可靠, 便于推广应用. 本方法为天 然气成藏年代学的研究提供了新思路, 值得进一步 深人研究.

致谢部分流体包裹体数据由施继锡研究员完成, 谨此致 谢. 本工作受中国科学院知识创新工程重要方向性项目 “煤成油气藏形成理论的研究”(KZCX2-110)和国家自然科 学基金(批准号: 40072043)资助.

\section{参考文献}

1 刘文汇, 徐永昌. 天然气中氩与源岩储层钾氩之关系. 见: 中科 院兰州地质研究所生物气体地球化学开放研究实验室研究年报 (1986). 兰州: 甘肃科学技术出版社, 1987. 191 200

2 戴金星, 烖厚发, 郝石生. 天然气地质学概论. 北京: 石油工业 出版社, 1989. 33 67

3 徐永昌, 王先彬, 吴仁铭, 等. 天然气中稀有气体同位素. 地球 化学, 1979, 8(4): $271 \sim 282$

4 Middleton D, Parnell J, Carey P, et al. Reconstruction of fluid migration history Northwest Ireland using fluid inclusion studies. Journal of Geochemical Exploration, 2000, 69-70: 633 677

5 Kelly J, Parnell J, Chen H G. Application of fluid inclusion to studies of fractured sandstone reservoirs. Journal of Geochemical Exploration, 2000, 69: 705 709

6 戴金星, 裴锡古, 紫厚发. 中国天然气地质学. 北京: 石油工业 出版社, 1992. $225 \sim 286$

7 Mclimans R. The application of fluid inclusions to migration of oil and diagenesis in petroleum reservoirs. Applied Geochemistry, 1987, 2(5-6): $585 \sim 603$

8 Murray R C. Hydrocarbon fluid inclusion in quartz. AAPG, 1957, 41(6): $950 \sim 952$

9 Tilley B J, Nesbitt B E, Longstaffe F J. Thermal history of Alberta deep basin: Comparative study of fluid inclusion and vitrinite reflectance data. AAPG, 1989,73(10): $1206 \sim 1222$

10 雷振宇, 张朝军. 鄂尔多斯盆地含油气系统. 勘探家, 1998, 3(1): $11 \sim 15$

11 闵琪. 深盆气藏与鄂尔多斯盆地. 低渗透油气田, 1998, 3(2): $1 \sim 6$

12 李振铎, 胡义军, 谭芳. 鄂尔多斯盆地上古生界深盆气研究. 天 然气工业, 1998, 18(3): 10 16

13 张文正, 李剑峰, 备川莉. 鄂尔多斯盆地上古生界深盆气形成 的气源条件研究. 低渗透油气田, 1998, 13(2): 13 23

14 刘孝汉, 王欣, 董钢, 等. 鄂尔多斯盆地上古生界气水分布和地 层压力. 低渗透油气田, 1989, 3(2): 32 36

15 任战利, 赵重远, 张军, 等. 鄂尔多斯盆地古地温研究. 沉积学 报, 1994, 12(1): $56 \sim 65$ 